\title{
Ventilation Inhomogeneities in Patients with Cystic Fibrosis: Which Target Lung Function Parameters Offer Valuable Evaluation?
}

\author{
Richard Kraemer ${ }^{a}$ b \\ ${ }^{a}$ Department of Clinical Research, University of Bern, and ${ }^{\mathrm{b}}$ Centre of Respiratory Medicine, Hirslanden Private \\ Hospital Group, Salem-Spital, Bern, Switzerland
}

The course of lung disease in patients with cystic fibrosis (CF) is largely characterized by recurrent episodes of pulmonary exacerbations, the number and severity of which influence the overall rate and deterioration of the disease. The day-to-day success or failure of the management of this disease determines the ultimate fate of most patients. The evaluation of lung function before versus after interventional treatment therefore plays a vital role in the clinical assessment of children and adults with CF. The selection of sound parameters which significantly and specifically determine changes in such interventional treatments is thus of great interest.

An example of this selection is the study by Vanderhelst et al. [1] published in this issue of Respiration, which demonstrates the clinical application of selective indices obtained by the nitrogen multibreath washout $\left(\mathrm{N}_{2} \mathrm{MBW}\right)$ technique, differentiating the treatment effect between conductive and acinar responses of ventilation inhomogeneities (VIH) following intravenous antibiotic treatment in adult CF patients.

$\mathrm{CF}$ is a complex, multiorgan disease with manifold interactions between genetic background, lung maturation, nutritional factors, viral and bacterial infections, energy expenditure, lung deterioration, and lung remodeling. The selection of sensitive outcome parameters depends on whether or not the parameters are sensitive enough to demonstrate a biological, clinically relevant response fol- lowing treatment. Statistically, such a response should be higher than the variability found in repeated baseline measurements, or it should exceed the 2-SD range of values predicted.

During the past decade, various groups have been working on multibreath washout (MBW) technology to adapt this noninvasive, practically cooperation-independent technique for use in all age groups of CF patients [2-13].

$\mathrm{MBW}$ is performed during tidal breathing by analyzing changes in the concentration of an exhaled inert tracer employing either (i) resident $\mathrm{N}_{2}$ that is 'washed out' using $100 \%$ oxygen in a semiopen system or (ii) an inhaled inert gas such as sulfur hexafluoride $\left(\mathrm{SF}_{6}\right)$, which has to be firstly 'washed in' in order to be 'washed out' in a second step. Both techniques provide a measure of VIH. In CF patients, such VIH can be defined by various parameters such as the lung clearance index (LCI), the moment ratio $\left(\mathrm{MR}=\mathrm{m}_{2} / \mathrm{m}_{0}\right)[4,14-18]$, curvilinearity indices $[1,19]$, and specific phase III slope indices of nonuniform gas mixing, especially in the conducting $\left(\mathrm{S}_{\text {cond }}\right)$ and acinar $\left(S_{\text {acin }}\right)$ airway zones $[1,6,20-22]$. Several commercial devices and test procedures for routine use have been developed during the past decade based on infrared or ultrasonic flowmeter technology. These facilitate more widespread usage of highly sensitive lung function techniques to enable early detection of CF lung disease throughout adulthood [5, 6, 8-13, 23-27].

\section{KARGER}

E-Mail karger@karger.com

www.karger.com/res
(C) 2014 S. Karger AG, Basel

0025-7931/14/0876-0459\$39.50/0
Prof. Richard Kraemer, MD

Kirchenfeldstrasse 74

CH-3005 Bern (Switzerland)

E-Mail richard.kraemer@ swissonline.ch 


\section{Strengths and Weaknesses of VIH Indices}

The MBW test has been advocated for small-airway detection in obstructive lung disease, and the most frequently reported MBW index is the LCI. It was first introduced in 1951 as a measure of overall lung ventilation heterogeneity [28] and was then adapted for use in children [2-4]. However, although the LCI is a popular subject of discussion [29], one must be aware that the LCI is just the ratio of the functional residual capacity (FRC) and the cumulative expired volume. The LCI is only an indirect measure of the ventilation distribution, largely dependent on changes in end-expiratory resting levels at FRC and most importantly significantly dependent on the breathing pattern [18].

Independent of the value of FRC is the mathematical treatment of the disturbed washout curve represented by the bending of the curve, which can be achieved by MR analysis [16] or estimates of curvilinearity [1, 19]. MR have shown clinical practicality [15-17] and were recently reevaluated [18]. Quantitatively, the moments can be understood as follows: $\mathrm{m}_{0}$ is simply the area under the washout curve, while $\mathrm{m}_{1}, \mathrm{~m}_{2}$, and higher moments are weighted values of tail segments under the washout curve. The ratio between the second and the zeroth moments $\left(\mathrm{m}_{2} / \mathrm{m}_{0}=\mathrm{MR}\right)$ of the $\mathrm{N}_{2} \mathrm{MBW}$ curve has recently been demonstrated to be a good index of VIH [18].

$S_{\text {cond }}$ and $S_{\text {acin }}$ represent the contributions of the conductive and acinar parts of the airways to $\mathrm{VIH}$, reflected in the alveolar slopes of the MBW. The former, referred to as convection-dependent VIH, originate from convective flow differences to and from different lung units because of differing pressure-volume characteristics of these units. The latter is referred to as diffusion-dependent $\mathrm{VIH}$, reflecting a far more complex diffusion-convection interaction process without the need for convective flow sequencing during expiration. $S_{\text {cond }}$, therefore, determines that part of the phase III MBW where only conductive airways are known to contribute to the MBW. In contrast, $\mathrm{S}_{\text {acin }}$ determines the VIH of that part attributed peripherally to the acinar entrance of the airways depicted from the slope of the first breath.

\section{Comparing Indices of VIH}

Regarding the advantages and disadvantages of all the indices for the evaluation of $\mathrm{VIH}$, it has to be recognized that LCI, MR, and $S_{\text {cond }}$ are largely dependent on the breathing pattern given by $\mathrm{V}_{\mathrm{T}} / \mathrm{FRC}$ [18]. It has been shown convincingly in children that fixed 1-liter breathing leads to a significant overestimation of the LCI. This is mainly due to breathing on a lower, nonphysiological end-expiratory level at FRC and hence altered ventilation on a resting lung volume closer to the residual volume. As a consequence, the ventilation distribution is impaired. The increase in VIH due to nonrelaxed natural breathing may be attributed to the fact that larger breaths open additional air spaces, leading to an overestimation of the FRC. The concordant increases in MR and $S_{\text {cond }}$ were both found not to be directly dependent on the FRC and seem to support this hypothesis of an increase in VIH with elevated $V_{\mathrm{T}}$ [18]. In CF, such mechanisms may play an even greater role since CF patients - both children and adults - suffer from a tremendous degree of both pulmonary hyperinflation and subsequent air trapping $[23,24$, 26].

\section{Conclusion}

The findings of Vanderhelst et al. [1] published in this issue of Respiration have to be considered in the context of limitation regarding the expressiveness of the changes obtained by $S_{\text {cond }}$ and $S_{\text {acin }}$. Following intravenous antibiotic treatment for exacerbation in adult patients with CF, the response to selected acinar rather than conductive VIH is a well-constructed clinical argument that can be easily understood. It would also be hoped that the conductive airways would be treated, leading to a better airway clearance, a reduction of pulmonary hyperinflation, and a decrease in trapped gases. In addition, it would be of real clinical interest to have the response to professional chest physiotherapy on VIH evaluated in a second, separate treatment step assessed by $S_{\text {cond }}$ and $S_{\text {acin }}$. Nevertheless, and most importantly, the replacement of the parameter $\mathrm{FEV}_{1}$ by target lung function parameters [30], which give a better insight into the complex changes of lung physiology in pre- versus postinterventional treatment trials, is long overdue.

\section{Acknowledgement}

The author thanks Ms. Dariel Anghilante (BSc Hons) for her critical appraisal and help with the English text. 


\section{References}

1 Vanderhelst E, De Meirleir L, Schuermans D, 11 Fuchs SI, Gappa M: Lung clearance index: Malfroot A, Vincken W, Verbanck S: Evidence of an acinar response following treatment for exacerbation in adult patients with cystic fibrosis. Respiration 2014;87:492-498.

$\checkmark 2$ Hutchison AA, Sum AC, Demis TA, Erben A, Landau LI: Moment analysis of multiple breath nitrogen washout in children. Am Rev Respir Dis 1982;125:28-32.

-3 Wall MA: Moment analysis of multibreath nitrogen washout in young children. J Appl Physiol 1985;59:274-279.

$\checkmark 4$ Kraemer R, Meister B: Fast real-time moment-ratio analysis of multibreath nitrogen washout in children. J Appl Physiol 1985;59: 1137-1144.

5 Verbanck S, Schuermans D, Van Muylem A, Melot C, Noppen M, Vincken W, Paiva M: Conductive and acinar lung-zone contributions to ventilation inhomogeneity in COPD. Am J Respir Crit Care Med 1998;157:15731577.

$\checkmark 6$ Gustafsson PM: Peripheral airway involvement in CF and asthma compared by inert gas washout. Pediatr Pulmonol 2007;42:168-176.

$>7$ Latzin P, Sauteur L, Thamrin C, Schibler A, Baldwin D, Hutten GJ, Kyburz M, Kraemer R, Riedel T, Frey U: Optimized temperature and deadspace correction improve analysis of multiple breath washout measurements by ultrasonic flowmeter in infants. Pediatr Pulmonol 2007;42:888-897.

-8 Horsley AR, Gustafsson PM, Macleod KA, Saunders C, Greening AP, Porteous DJ, Davies JC, Cunningham S, Alton EW, Innes JA: Lung clearance index is a sensitive, repeatable and practical measure of airways disease in adults with cystic fibrosis. Thorax 2008;63: 135-140.

9 Fuchs SI, Eder J, Ellemunter H, Gappa M: Lung clearance index: normal values, repeatability, and reproducibility in healthy children and adolescents. Pediatr Pulmonol 2009; 44:1180-1185.

10 Robinson PD, Lindblad A, Gustafsson PM: Comparison of the utility of multiple breath inert gas washout parameters in cystic fibrosis. Thorax 2010;65:659. clinical and research applications in children. Paediatr Respir Rev 2011;12:264-270.

12 Aurora P, Stanojevic S, Wade A, Oliver C, Kozlowska W, Lum S, Bush A, Price J, Carr SB, Shankar A, Stocks J: Lung clearance index at 4 years predicts subsequent lung function in children with cystic fibrosis. Am J Respir Crit Care Med 2011;183:752-758.

13 Verbanck S, Thompson BR, Schuermans D, Kalsi H, Biddiscombe M, Stuart-Andrews C, Hanon S, Van Muylem A, Paiva M, Vincken W, Usmani O: Ventilation heterogeneity in the acinar and conductive zones of the normal ageing lung. Thorax 2012;67:789-795.

14 Couriel JM, Schier M, Hutchison AA, Phelan PD, Landau LI: Distribution of ventilation in young children with cystic fibrosis. Pediatr Pulmonol 1985;1:314-318.

15 Kraemer R, Schoni MH: Ventilatory inequalities, pulmonary function and blood oxygenation in advanced states of cystic fibrosis. Respiration 1990;57:318-324.

16 Schibler A, Schneider M, Frey U, Kraemer R: Moment ratio analysis of multiple breath nitrogen washout in infants with lung disease. Eur Respir J 2000;15:1094-1101.

17 Aurora P, Kozlowska W, Stocks J: Gas mixing efficiency from birth to adulthood measured by multiple-breath washout. Respir Physiol Neurobiol 2005;148:125-139.

18 Yammine S, Singer F, Gustafsson P, Latzin P: Impact of different breathing protocols on multiple-breath washout outcomes in children. J Cyst Fibros 2014;13:190-197.

19 Verbanck S, Paiva M, Paeps E, Schuermans D, Malfroot A, Vincken W, Vanderhelst E: Lung clearance index in adult cystic fibrosis patients: the role of convection-dependent lung units. Eur Respir J 2013;42:380-388.

20 Horsley AR, Macleod KA, Robson AG, Lenney J, Bell NJ, Cunningham S, Greening AP, Gustafsson PM, Innes JA: Effects of cystic fibrosis lung disease on gas mixing indices derived from alveolar slope analysis. Respir Physiol Neurobiol 2008;162:197-203.
21 Van Muylem A, Baran D: Overall and peripheral inhomogeneity of ventilation in patients with stable cystic fibrosis. Pediatr Pulmonol 2000;30:3-9.

22 Abbas C, Singer F, Yammine S, Casaulta C, Latzin P: Treatment response of airway clearance assessed by single-breath washout in children with cystic fibrosis. J Cyst Fibros 2013;12:567-574.

23 Kraemer R, Blum A, Schibler A, Ammann RA, Gallati S: Ventilation inhomogeneities in relation to standard lung function in patients with cystic fibrosis. Am J Respir Crit Care Med 2005;171:371-378.

-24 Kraemer R, Baldwin DN, Ammann RA, Frey $\mathrm{U}$, Gallati S: Progression of pulmonary hyperinflation and trapped gas associated with genetic and environmental factors in children with cystic fibrosis. Respir Res 2006;7:138.

25 Robinson PD, Goldman MD, Gustafsson PM: Inert gas washout: theoretical background and clinical utility in respiratory disease. Respiration 2009;78:339-355.

26 Kraemer R, Latzin P, Pramana I, Ballinari P, Gallati S, Frey U: Long-term gas exchange characteristics as markers of deterioration in patients with cystic fibrosis. Respir Res 2009; 10:106.

27 Verbanck S, Paiva M, Schuermans D, Malfroot A, Vincken W, Vanderhelst E: Acinar and conductive ventilation heterogeneity in severe CF lung disease: back to the model. Respir Physiol Neurobiol 2013;188:124-132.

28 Becklake MR: A new index of the intrapulmonary mixture of inspired air. Thorax 1952;7: 111-116.

29 Kent L, Reix P, Innes JA, Zielen S, Le Bourgeois $\mathrm{M}$, Braggion $\mathrm{C}$, Lever S, Arets $\mathrm{HG}$, Brownlee K, Bradley JM, Bayfield K, O'Neill K, Savi D, Bilton D, Lindblad A, Davies JC, Sermet I, De Boeck K: Lung clearance index: evidence for use in clinical trials in cystic fibrosis. J Cyst Fibros 2014;13:123-138.

30 Stick SM, Sly PD: Exciting new clinical trials in cystic fibrosis: infants need not apply. Am J Respir Crit Care Med 2011;183:1577-1578.
Ventilation Inhomogeneities in Patients with Cystic Fibrosis
Respiration 2014;87:459-461 DOI: $10.1159 / 000362675$ 